REVIEW ARTICLE

\title{
Robust increases in erythropoietin production by the hypoxic fetus is a response to protect the brain and other vital organs
}

Kari A. Teramo ${ }^{1}$, Miira M. Klemetti ${ }^{1}$ and John A. Widness ${ }^{2}$

Fetal erythropoietin (EPO), in addition to regulating erythropoiesis, has also tissue-protective properties based on its antiinflammatory, anti-apoptotic, antioxidant, and neurotrophic effects. Notably, EPO concentrations needed for tissue protection are 100-1000 times higher than concentrations needed for regulating erythropoiesis. This dual effect of EPO is based on EPO-receptor (EPO-R) isoforms, which differ structurally and functionally. We hypothesize in this Integrated Mechanism Review that during severe fetal hypoxia the observed, but poorly understood, marked increases of fetal plasma EPO concentrations occur to protect the brain, heart, and other vital fetal organs. We further hypothesize that the concurrent marked increases of EPO in the amniotic fluid during fetal hypoxia, occur to protect newborn infants from necrotizing enterocolitis. This review presents experimental and clinical evidence in support of these hypotheses and points out unknown or poorly understood functions of EPO in the fetus. If these novel hypotheses are correct, the importance of fetal EPO as an antenatal hypoxia biomarker will become apparent. It will also likely point the way to important diagnostic and therapeutic fetal and neonatal interventions.

Pediatric Research (2018) 84:807-812; https://doi.org/10.1038/s41390-018-0054-4

\section{BACKGROUND}

Erythropoietin (EPO), a glycoprotein hormone with a molecular weight of $30.4 \mathrm{kDa}$, is primarily responsible for regulating erythrocyte production in adults, newborn infants, and fetuses. ${ }^{1}$ During pregnancy, maternal serum EPO levels increase linearly from 16 to $65 \mathrm{mU} / \mathrm{ml}$ at term to meet the hematopoietic needs of pregnancy. ${ }^{2}$ Prior to 30 weeks of gestation in the fetus, the liver is the main organ of EPO production, after which a gradual transition to renal EPO production occurs. ${ }^{3,4}$ During normal oxygenation at term, fetal EPO production takes place mainly in the kidneys. ${ }^{4}$ Because EPO is not stored in tissue and does not cross the placenta, ${ }^{5}$ steady-state fetal plasma EPO concentration reflects equal, opposing rates of EPO synthesis, and elimination. During the last trimester of normal pregnancy, normoxemic human fetal plasma EPO hormone concentrations range from 10 to $50 \mathrm{mU} / \mathrm{ml}$ prior to labor. ${ }^{6,7}$ Concurrent amniotic fluid EPO concentrations during normal fetal oxygenation range from 2 to $20 \mathrm{mU} / \mathrm{ml}^{6}{ }^{6}$ Fetal plasma EPO concentrations under both normal and fetal hypoxemic conditions average 2.6 times higher than concurrent amniotic fluid EPO levels. ${ }^{6}$

This Integrated Mechanism Review ${ }^{8}$ focuses on important nonhematological actions of EPO that are being increasingly recognized in the fetus and the newborn infant. ${ }^{9,} 10$ Our central hypothesis is that the observed marked increases of fetal EPO during severe fetal hypoxia occurs in order to protect its brain, heart, and other vital organs from the deleterious effects of severe hypoxia. We further hypothesize that the purpose of the concurrent increase in amniotic fluid EPO concentration during severe fetal hypoxia is to protect the intestine from necrotizing enterocolitis (NEC). In this review, the known effects of EPO on fetal erythropoiesis and its tissue-protective properties are described to support these hypotheses based on existing experimental and clinical evidence. If our hypotheses are correct, they will further emphasize the importance of fetal EPO as an important antenatal hypoxia biomarker, and suggest potential new therapeutic approaches.

Several unknown or poorly understood EPO effects in the fetus include: (1) what is the contribution and the role of the placenta in increasing fetal EPO production during hypoxia?; (2) how and through what mechanism is amniotic fluid EPO concentration also increased during fetal hypoxia?; (3) how and through what mechanism does fetal EPO reach the intestine?; and (4) through what mechanism and in which fetal organs does EPO exert protective effects during tissue hypoxia? As a basis for clarifying these uncertainties, Fig. 1 depicts maternal EPO production during normal pregnancy and the postpartum period. It also depicts fetal EPO production during anemia and chronic hypoxia in the context of previously documented or hypothetical effects of EPO on the fetus and the newborn infant.

Role of EPO in fetal red cell production

Fetal red cell production is regulated by EPO to maintain normal steady-state erythropoiesis and blood hemoglobin levels during normoxemic conditions and to accelerate erythropoiesis during tissue hypoxia due to anemia and other causes ${ }^{1,3,4}$ (Fig. 1). EPO synthesis is regulated by the partial pressure of oxygen $\left(\mathrm{pO}_{2}\right)$ of blood perfusing the oxygen sensitive renal peritubular fibroblasts, where it is mediated by the hypoxia-inducible transcription factor (HIF) complex. ${ }^{11-13}$

EPO in amniotic fluid

Amniotic fluid EPO concentrations correlate highly with fetal plasma EPO concentrations both in normal and abnormal

\footnotetext{
${ }^{1}$ Department of Obstetrics and Gynecology, Helsinki University Hospital, University of Helsinki, Helsinki, Finland and ${ }^{2}$ Stead Family Department of Pediatrics, University of lowa, lowa City, IA, USA

Correspondence: Kari A. Teramo (kari.teramo@hus.fi)
}

Received: 18 January 2018 Revised: 16 March 2018 Accepted: 22 March 2018

Published online: 12 June 2018 


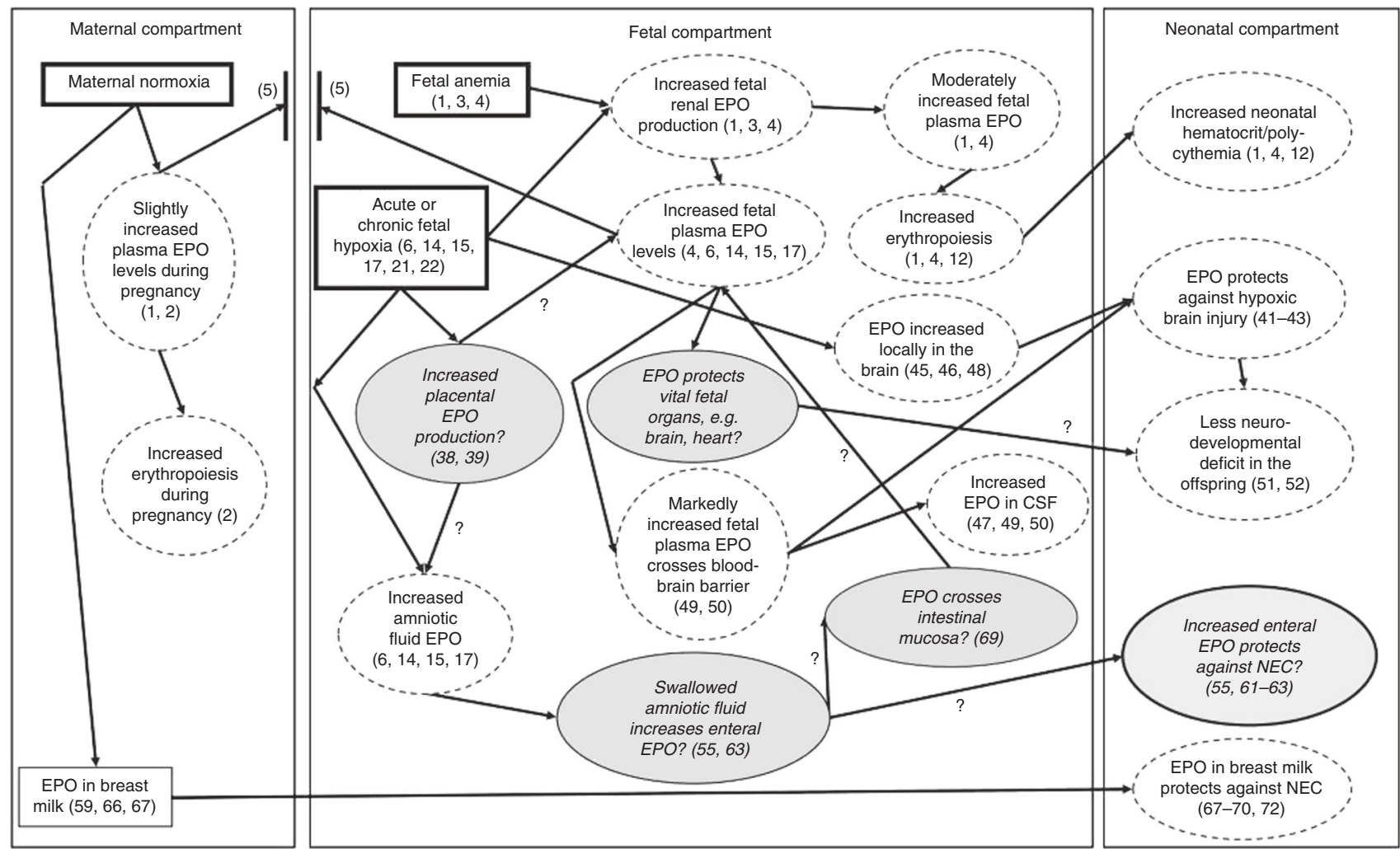

Fig. 1 Proposed physiological and pathophysiological mechanistic framework of erythropoietin (EPO) production and actions during fetal anemia and during acute and chronic hypoxia. Illustrated are EPO's effects in the maternal, fetal, and neonatal compartments based on referenced supporting evidence from both basic research and clinical/epidemiologic studies. Maternal normoxia, fetal anemia, and acute or chronic fetal hypoxia (indicated by bold rectangles) form the starting points of EPO effects. Known effects of EPO are indicated by bold lettering within dashed-line ovals and pointing arrows without question marks. Unknown or poorly understood mechanisms are indicated in italics with question marks within ovals with gray background and question marks included between these ovals and dashed-lined ovals indicating uncertain relationships. The protective effect of breast milk EPO on the neonatal intestine for avoiding necrotizing enterocolitis (NEC) is also indicated. The maternal, fetal, and neonatal compartments are separated by the lines between the compartments. The two bold, vertical short lines between the maternal and fetal compartments depicts the placenta. The numbers in parentheses indicate the references.

pregnancies. $^{6}$ In pregnancies complicated by type 1 diabetes or hypertension, amniotic fluid EPO concentrations obtained within 2 days before birth and prior to labor are highly correlated with fetal plasma EPO concentrations, $r=0.86$ and $r=0.89$, respectively. ${ }^{14,15}$ In these pregnancies, both normal amniotic fluid EPO levels (i.e., $<20 \mathrm{mU} / \mathrm{ml}$ ) and pathologically elevated amniotic fluid EPO levels (i.e., $>50 \mathrm{mU} / \mathrm{ml}$ ) correlate highly significantly with fetal plasma EPO levels (Fig. 2). In contrast, slightly elevated (i.e., 20-50 $\mathrm{mU} / \mathrm{ml}$ ) do not. The latter may be explained by a delay in the increase in amniotic fluid EPO concentration relative to the rate of increase in fetal plasma EPO concentration during fetal hypoxia. ${ }^{16}$

Serial measurements of amniotic fluid EPO levels in individual pregnancies demonstrate that once the fetus becomes hypoxic, the amniotic fluid EPO concentration starts to increase exponentially. ${ }^{14,15,17}$ It is noteworthy from serial amniotic fluid EPO measurements in individual cases that once amniotic fluid EPO levels reach pathological levels (i.e., $>50 \mathrm{mU} / \mathrm{ml}$ ), amniotic fluid concentrations increase exponentially. ${ }^{14,15}$ Calculated from these exponential amniotic fluid EPO increases, the daily increase in amniotic fluid EPO levels can be as much as $30-40 \mathrm{mU} / \mathrm{ml} .^{15}$ This is equivalent to daily increases of $\sim 80-100 \mathrm{mU} / \mathrm{ml}$ in plasma during fetal hypoxia. Once fetal hypoxia triggers increased fetal EPO production, pathological amniotic fluid EPO levels do not level off or decrease; instead, they continue to increase. ${ }^{14}, 15,17$

In clinical intrauterine red cell transfusion studies of Rhimmunized pregnancies, fetal hemoglobin concentrations ranging from 11 to $159 \mathrm{~g} / \mathrm{l}$ obtained at the first cordocentesis-and thus prior to fetal red cell transfusion-correlate inversely with

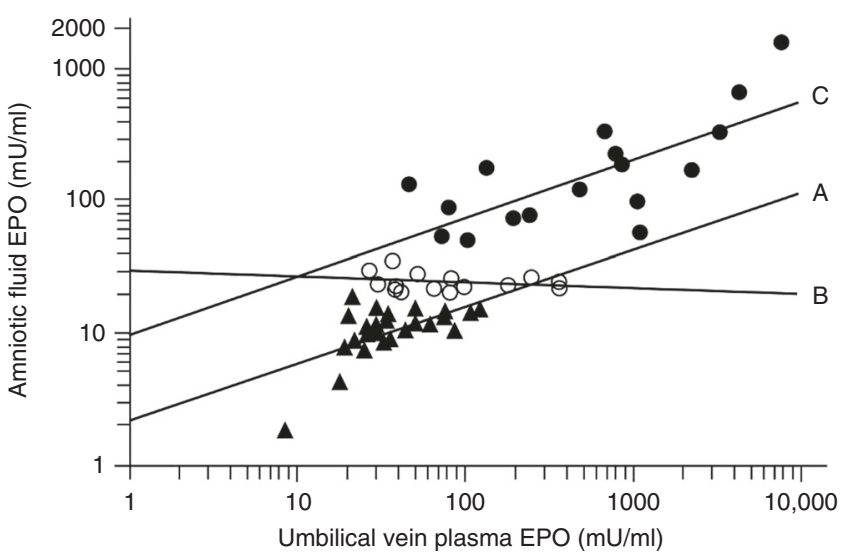

Fig. 2 Relationship of fetal plasma and amniotic fluid EPO in pregnancies complicated by preeclampsia or hypertension grouped by amniotic fluid EPO concentration: A low EPO $<20 \mathrm{mU} / \mathrm{ml}, r=$ $0.87, p<0.0001, n=28$; B slightly elevated EPO $20-50 \mathrm{mU} / \mathrm{ml}, r=$ $-0.10, p=\mathrm{NS} ; n=13$; and C high EPO $>50 \mathrm{mU} / \mathrm{ml}, r=0.86, p<$ $0.0001, n=17$. (Reproduced with permission from $\mathrm{S}$. Karger AG, Basel published in Neonatology 95:105-116 (2009))

concurrent amniotic fluid EPO levels that range from 2 to 42 $\mathrm{mU} / \mathrm{ml}^{16}$ This correlation and the slopes of this relationship are similar before and after 27 weeks of gestation $(r=-0.57$ and $r=$ -0.49 , respectively). This observation is consistent with the 
observation that only low circulating EPO concentrations are required for red cell production even when fetal hemoglobin levels are extremely low. ${ }^{18}$ Despite this, even anemic fetuses markedly increase their EPO production as indicated by exponential increases in amniotic fluid EPO levels when already anemic fetuses become severely hypoxic. ${ }^{17}$ This suggests a different function for EPO under these circumstances.

It is unknown how EPO reaches amniotic fluid in human pregnancy. In the ovine pregnancy EPO mRNA and EPO hormone are both present in the fetal amnion and chorion membranes during the last trimester of pregnancy. ${ }^{19}$ This indicates that EPO is functionally active in the ovine fetal membranes and that the membranes could be one of the sources of EPO in the amniotic fluid. ${ }^{19}$ The relative contributions of potential sources of EPO and the transport mechanisms of fetal EPO into the amniotic fluid in human pregnancy is currently unknown. To address this potentially clinically important issue, there is an urgent need for this to be studied both in animal models and human pregnancies.

\section{Chronic fetal hypoxia and EPO}

As in adults, tissue hypoxia in the fetus is the major stimulus of EPO production. ${ }^{3}$ In adults, plasma EPO levels start to increase 90 min after the beginning of acute hypoxia, with the magnitude of the increase correlating directly with the duration and severity of hypoxia. ${ }^{20}$ In the fetal sheep, plasma EPO levels begin to increase 3-4 $\mathrm{h}$ after a massive acute hemorrhage or after induction of moderate to severe fetal hypoxia. ${ }^{21,} 22$ In human pregnancy both umbilical cord plasma and amniotic fluid EPO levels correlate inversely with umblical artery (UA), $\mathrm{pH}$, base excess and $\mathrm{pO}_{2}$, and directly with $\mathrm{pCO}_{2}$ and lactate in cases of fetal chronic hypoxia. $6,14,15,17,23-25$ In the fetal sheep, plasma EPO levels start to increase exponentially when the arterial oxygen content falls below $60 \%$ of normal. ${ }^{26} \mathrm{~A}$ similar exponential increase in amniotic fluid EPO levels has been observed in human type 1 diabetic pregnancies when $\mathrm{UA} \mathrm{pO}_{2}$ levels decrease below $2.0 \mathrm{kPa}$ $(15.0 \mathrm{mmHg})^{14}$

Hypoxia increases both reactive oxygen species $(\mathrm{ROS})^{27,} 28$ and reactive nitrogen species (RNS). ${ }^{27}$ The degree of fetal oxidative stress can be quantitated by measuring the concentration of specific oxidative and nitrosative stress biomarkers in amniotic fluid. ${ }^{29}, 30$ In support of this we have reported in diabetic pregnancies that amniotic fluid EPO levels correlate highly significantly with two amniotic fluid oxidative stress biomarkers (meta-L-tyrosine/Phe and 8-oxodG/2dG ratios) and one nitrosative stress biomarker (3-nitro-L-tyrosine/Phe ratio) $(r=0.59, r=0.93$, and $r=0.90$, all $p<0.001) .{ }^{27}$ While this association further emphasizes the importance of fetal EPO level as a marker of intrauterine hypoxia, the nature of and the possible mechanisms responsible for this association are unknown. Once discovered, new therapeutic approaches might become apparent.

Increased fetal umbilical cord blood or amniotic fluid EPO levels have been reported in a broad spectrum of pregnancies in which fetal hypoxia occurs. These include prolonged pregnancies ${ }^{31}$ and pregnancies complicated by meconium-stained amniotic fluid, $^{32,33}$ growth-restricted fetuses, ${ }^{15,34,35}$ abnormal fetal heart rate recordings, ${ }^{36,}{ }^{37}$ type 1 diabetes, ${ }^{14}$ hypertension, ${ }^{15}$ and severe fetal anemia. ${ }^{17}$ While clinical evidence of increased hypoxia in fetuses or asphyxia in newborn infants are common among all these abnormal antepartum situations, the pathogenic mechanisms leading to fetal hypoxia differ among these conditions.

\section{Placental EPO production}

In the ovine fetus, a switch of EPO synthesis from the kidneys to the placenta occurs during hypoxia. ${ }^{38}$ In the study by Davis et al., ${ }^{38}$ placental production of EPO was not observed during normal fetal oxygenation. However, after inducing fetal hypoxia, umbilical vein (UV) EPO concentrations increased to levels $13 \%$ higher than UA concentrations, thereby suggesting increased placental EPO production. The investigators calculated that the placenta produced 1.1 million $\mathrm{mU}$ of EPO per hour during hypoxia. This value is 15 times greater than simultaneously measured EPO production by the fetal kidneys. ${ }^{38}$ Similarly, when we measured UV and UA EPO plasma concentrations separately at birth in type 1 diabetic pregnancies delivered during elective cesarean section before labor, UV EPO levels were significantly higher than UA levels in hypoxic fetuses with $\mathrm{UA} \mathrm{pO}_{2}$ below $2 \mathrm{kPa}(15 \mathrm{mmHg})$ at delivery. ${ }^{39}$ In addition, our observation that the UV/UA plasma EPO ratio correlated inversely with $\mathrm{UA} \mathrm{pO}_{2}{ }^{39}$ further indicates that placental EPO production increases during fetal hypoxia. We, therefore, speculate that the observed increased fetal plasma EPO concentrations in human pregnancy is at least partially a function of the increased placental EPO synthesis during fetal hypoxia in order to protect the fetal brain and other vital organs (Fig. 1).

Although EPO protein, mRNA and receptors are all present in both the human and ovine placenta, ${ }^{40,41}$ their functional importance for the fetus is not well understood. Clearly, the transport mechanisms of placental EPO hormone into the fetal circulation needs to be delineated during normal and hypoxic conditions in human pregnancies.

In addition to these uncertainties of placental EPO production and transport, very little is known about how factors such as chorioamnionitis or drugs might interfere with, or otherwise modulate fetal EPO production and transport. If our hypothesis that fetal EPO synthesis is increased during fetal hypoxia to protect its brain and other vital organs is correct, it will emphasize the clinical importance and utility of antenatal EPO measurement in amniotic fluid and fetal plasma at birth. This is especially important in pregnancies at an increased risk of fetal hypoxic sequelae. Finally, the use of amniotic fluid EPO levels as an antenatal hypoxia marker and predictor of poor neurodevelopmental outcome needs to be addressed in adequately powered single and multi-center randomized clinical trials. It is imperative that such randomized clinical trials include follow-up studies of subsequent cognitive functions.

Role of EPO in tissue protection

In addition to its role in hematopoietic regulation, EPO also has tissue-protective properties. ${ }^{41-43}$ This is the result of EPO receptor (EPO-R) isoforms, which differ structurally and functionally from the hematopoietic EPO-R isoform. Different EPO-Rs exert both shortand long-term tissue-protective effects. ${ }^{41}$ Acute, short-term EPO effects are mediated by its anti-inflammatory, anti-apoptotic, and antioxidant properties. ${ }^{41-43}$ Long-term EPO effects are those promoting more gradual processes, including erythropoiesis, angiogenesis, and neurogenesis. ${ }^{42}$ In vivo and in vitro studies indicate that high EPO concentrations and short receptor occupancy are required to activate the tissue-protective isoform of EPO-R with a relatively low EPO affinity. ${ }^{41}$ In contrast, much lower but sustained concentrations of EPO are needed for the regulation of erythropoiesis as the high-affinity EPO-R isoform is expressed by proerythrocytes during erythrocyte maturation. ${ }^{11,13,41}$

EPO and the fetal brain. During acute and chronic hypoxia, the fetus redistributes cardiac output to maintain adequate oxygen supply to the brain. This brain-sparing redistribution of cardiac output is a well known fetal adaptive mechanism to counteract deleterious effects of chronic hypoxia. ${ }^{44}$ In addition, local EPO production has been shown to take place in the fetal brain. ${ }^{45}$ This is based on EPO and EPO-R gene expression in astrocytes, glial cells, neurons, and brain endothelial cells. ${ }^{46}$ In asphyxiated newborn infants in the first two days of life, cerebrospinal fluid (CSF) EPO concentrations correlate highly significantly with concurrent plasma EPO concentrations $(r=0.99, p<0.0001){ }^{47}$ Hence, local endogenous EPO production in CNS tissue is another adaptive mechanism to attenuate the harmful effects of hypoxia on the brain. ${ }^{48}$ 
Numerous preclinical, and more recently, clinical studies in preterm newborn infants have shown that exogenously administered recombinant human EPO (rhEPO) has neuroprotective effects in the brain (for review see ref. ${ }^{42}$ ). As proof that EPO can cross the blood-brain barrier, marked increases in CSF EPO levels are observed in fetal sheep within $2-4 \mathrm{~h}$ after a high dose of parenteral rhEPO to levels shown to offer tissue protection from hypoxia. ${ }^{49,} 50$ What remains uncertain is whether the high EPO levels in the CSF are caused by high plasma EPO levels crossing the blood-brain barrier during hypoxia or the result of local EPO production by brain tissue (Fig. 1). This missing information has important therapeutic implications. It is noteworthy that EPO concentrations of over $10,000 \mathrm{mU} / \mathrm{ml}$ have been measured in cord blood plasma at birth of asphyxiated fetuses. ${ }^{14,15}$ Hence, we infer that EPO can cross the fetal blood-brain barrier in human pregnancies.

There is growing evidence that preterm infants weighing $<1000 \mathrm{~g}$ at birth experience neuroprotective benefit from rhEPO treatment given to stimulate erythropoiesis. ${ }^{51}$ Newborn infants with severe intraventricular hemorrhage receiving rhEPO had better neurodevelopmental outcome at the age of 10 to 13 years than those not receiving rhEPO during the neonatal period. ${ }^{51}$ Although therapeutic body cooling is presently the method of choice of term newborn infants suffering from hypoxic-ischemic encephalopathy (HIE), almost half of HIE survivors have severe neurologic sequelae. High dose rhEPO parenteral treatment added to cooling treatment of newborn infants with HIE resulted in smaller brain injury volume than cooling treatment alone as detected by MRI. ${ }^{52}$ As expected, the neurodevelopmental outcome was poorer at 12 months of age among the newborn infants receiving cooling treatment alone compared to those receiving both EPO and cooling treatment. ${ }^{52}$

Amniotic fluid and the neonatal intestine. Amniotic fluid contains a large number of cytokines, including EPO, and antimicrobial peptides known to influence the development of fetal gastrointestinal tract. $^{53,54}$ It is noteworthy that NEC does not exists in the fetus, which has led to the speculation that amniotic fluid has protective effects against NEC. ${ }^{54}$ Although the possible protective functions of amniotic fluid against NEC has recently been reviewed, ${ }^{55}$ a plausible explanation of how amniotic fluid exerts its protective effects against NEC in the newborn infant has not been given. ${ }^{55}$

It is well known that perinatal asphyxia is associated with neonatal gut injury, impaired intestinal motility, and NEC. ${ }^{56-58}$ Notably, EPO receptors are present both in human and rat enterocytes. ${ }^{59}$ Parenteral rhEPO given to newborn infants weighing $\leq 1250 \mathrm{~g}$ at birth has been associated with a decrease in the incidence of NEC. ${ }^{60}$ Moreover, in a neonatal rat model of NEC, exogenous EPO has been shown to protect intestinal cells both in vitro and in vivo ${ }^{61}$ and to stimulate vasculogenesis of microvascular endothelial intestine cells. ${ }^{62}$ In a recent randomized controlled study in preterm newborn infants both recombinant human granulocyte colony-stimulating factor (rhG-CSF) and rhEPO, administered enterally separately or in combination during the first days of life, decreased the risk of NEC and improved feeding outcomes. ${ }^{63}$

An important unanswered question with potential therapeutic implications for NEC is why amniotic fluid EPO concentration increases exponentially during fetal hypoxia. ${ }^{14,15,17}$ We hypothesize that high amniotic fluid EPO concentrations associated with fetal hypoxia exert beneficial effects on the fetal and neonatal intestine as a result of fetal swallowing of amniotic fluid with high EPO concentration (Fig. 1). It is well known that the near-term fetus swallows up to $700 \mathrm{ml}$ of amniotic fluid daily. ${ }^{64,}{ }^{65}$ In this regard, it is noteworthy that EPO in milk resists degradation in the intestine of the newborn infant. ${ }^{66,67}$ Although EPO concentrations greater than $1500 \mathrm{mU} / \mathrm{ml}$ have been measured in the amniotic fluid during fetal hypoxia, ${ }^{14,15}$ the potential beneficial effects of these markedly increased levels of amniotic fluid EPO in reducing neonatal intestine hypoxic tissue injury has yet to be determined. If these beneficial effects are shown, therapeutic EPO given enterally or parenterally would be the next important step to study.

The current widely accepted practice of human milk feeding as an important approach to NEC prevention in preterm newborn infants $^{66}$ lends further support to our hypothesis that increased amniotic fluid EPO levels exert beneficial effects on the fetal and neonatal intestine. The beneficial effects of human milk on the intestine of preterm newborn infants has been shown at least in part to be due to high levels of EPO and other growth factors in the breast milk. ${ }^{67}$ EPO levels in human milk are similar to maternal plasma EPO levels in the early postpartum period. EPO levels in breast milk increase above maternal plasma EPO levels during ongoing nursing, thus suggesting active secretion of EPO by the mammary gland ${ }^{68}$ (Fig. 1).

Presently, there is controversy whether enteral EPO is absorbed intact into the circulation of the newborn offspring. ${ }^{69,} 70$ In a rat model, parenterally increased plasma EPO in dams did not increase plasma EPO levels or hematocrit in suckling rats compared with controls. ${ }^{70}$ However, enterally administered ${ }^{125} \mathrm{I}-$ rhEPO did show enteral absorption in suckling rats with $5 \%$ of the total EPO dose administered being found in the plasma and another $8-10 \%$ localized in the bone marrow. ${ }^{69}$ Radiolabeled rhEPO was also found localized in liver and other solid tissues. In suckling rats, a high dose of EPO $\left(1700 \mathrm{U} \mathrm{kg}^{-1} \times \mathrm{day}^{-1}\right)$ fed artificially together with iron sulfate was shown to increase hemoglobin levels. ${ }^{71}$ In another study, enteral administration of EPO to preterm infants was shown to stimulate erythropoiesis. ${ }^{72}$ It can be concluded from these studies that enteral absorption of EPO into the circulation seems possible. Nonetheless, it is clear that more studies are needed to delineate the circumstances that determine enteral absorption of EPO in newborns. Whether enteral absorption of EPO into the fetal circulation also occurs with swallowed amniotic fluid EPO in human pregnancies is unknown.

In conclusion, in addition to the role of EPO as a regulator of erythropoiesis, EPO also exerts both short- and long-term tissueprotective effects. This dual role of EPO is based on different EPO receptor isoforms. Notably, EPO's tissue-protective effect requires markedly higher EPO concentrations than its hematopoietic effects. In human pregnancy, we and others have measured extremely high levels of EPO in fetal plasma and in the amniotic fluid. The functional significance of this is not well understood. Here, we hypothesize that the fetus increases its EPO production in order to protect its brain and other vital organs. We further hypothesize, based on fetal swallowing of amniotic fluid, that the fetus increases amniotic fluid EPO levels during fetal hypoxia to protect the intestine during the neonatal period. In this Mechanistic Integrated Review, we suggest a new way of looking at the effects of EPO on fetal erythropoiesis, as well as EPO's central nervous and gut tissue-protective properties. Our hypotheses are based on a review the literature of both experimental and clinical studies. If our hypotheses are correct, the importance of fetal EPO as an antenatal hypoxia biomarker and therapeutic agent will become apparent and provide an urgently needed impetus for confirming our hypotheses and exploring fetal EPO's diagnostic and therapeutic potential.

\section{ACKNOWLEDGEMENTS}

We acknowledge and appreciate the valuable editorial and secretarial assistance provided by Mark Hart. Funding JAW received support for this work from NIH NHLBI Program Project Grant P01 HL046925.

\section{ADDITIONAL INFORMATION}

Competing interests: The authors declare no competing interests. 
Publisher's note: Springer Nature remains neutral with regard to jurisdictional claims in published maps and institutional affiliations.

\section{REFERENCES}

1. Jelkmann, W. Physiology and pharmacology of erythropoietin. Transfus. Med. Hemother. 40, 302-309 (2013).

2. Cotes, P. M., Canning, C. E. \& Lind, T. Changes in serum immunoreactive erythropoietin during the menstrual cycle and normal pregnancy. Br. J. Obstet. Gynaecol. 90, 304-311 (1983).

3. Dame, C. et al. Erythropoietin mRNA expression in human fetal and neonatal tissue. Blood 92, 3218-3225 (1998).

4. Moritz, K. M., Lim, G. B. \& Wintour, E. M. Developmental regulation of ery thropoietin and erythropoiesis. Am. J. Physiol. 272, R1829-R1844 (1997)

5. Widness, J. A., Schmidt, R. L. \& Sawyer, S. T. Erythropoietin transplacental passage —review of animal studies. J. Perinat. Med. 23, 61-70 (1995).

6. Teramo, K. A. et al. Amniotic fluid erythropoietin correlates with umbilical plasma erythropoietin in normal and abnormal pregnancy. Obstet. Gynecol. 69, 710-716 (1987).

7. Forestier, F., Daffos, F., Catherine, N., Renard, M. \& Adreux, J. P. Developmental hematopoiesis in normal human fetal blood. Blood 77, 2360-2363 (1991).

8. Dammann, O. \& Gressens, P. Integrated mechanism reviews. Pediatr. Res. 71, 530 531 (2012)

9. Arcasoy, M. O. Non-erythroid effects of erythropoietin. Haematologica 95, 1803-1805 (2010).

10. Nekoui, A. \& Blaise, G. Erythropoietin and nonhematopoietic effects. Am. J. Med Sci. 353, 76-81 (2017).

11. Semenza, G. L. Regulation of mammalian $\mathrm{O}_{2}$ homeostasis by hypoxia-inducible factor 1. Annu. Rev. Cell Dev. Biol. 15, 551-578 (1999).

12. Jelkmann, W. Erythropoietin after a century of research: younger than ever. Eur. J. Haematol. 78, 183-205 (2007).

13. Brines, M. \& Cerami, A. Erythropoietin-mediated tissue protection: reducing collateral damage from the primary injury response. J. Intern. Med. 264, 405-432 (2008).

14. Teramo, K., Kari, M. A., Eronen, M., Markkanen, H. \& Hiilesmaa, V. High amniotic fluid erythropoietin levels are associated with an increased frequency of fetal and neonatal morbidity in type 1 diabetic pregnancy. Diabetologia 47, 1695-1703 (2004).

15. Teramo, K. A., Hiilesmaa, V. K., Schwartz, R., Clemons, G. K. \& Widness, J. A. Amniotic fluid and cord blood plasma erythropoietin levels in pregnancies complicated by preeclampsia, pregnancy-induced hypertension and chronic hypertension. J. Perinat. Med. 32, 240-247 (2004).

16. Teramo, K. A. \& Widness, J. A. Increased fetal plasma and amniotic fluid erythropoietin concentrations: Markers of intrauterine hypoxia. Neonatology 95 105-116 (2009).

17. Voutilainen, P. J., Widness, J. A., Clemons, G. K., Schwartz, R. \& Teramo, K. Amniotic fluid erythropoietin predicts fetal distress in Rh-immunized pregnancies. Am. J. Obstet. Gynecol. 160, 429-434 (1989).

18. Freise, K.J., Widness, J. A., \& Veng-Pedersen, P. Erythropoietic response to endogenous erythropoietin in premature very low birth weight infants. J. Pharmacol Exp. Ther. 332, 229-237 (2010).

19. Kim, M. J., Bogic, L., Cheung, C. Y. \& Brace, R. A. Expression of erythropoietin mRNA, protein and receptor in ovine fetal membranes. Placenta 22, 846-851 (2001).

20. Eckardt, K. U. et al. Rate of erythropoietin formation in humans in response to acute hypobaric hypoxia. J. Appl. Physiol. 66, 1785-1788 (1989).

21. Widness, J. A. et al. Temporal response of immunoreactive erythropoietin to acute hypoxemia in fetal sheep. Pediatr. Res. 20, 15-19 (1986).

22. Kim, S. J., Cheung, C. Y., Widness, J. A. \& Brace, R. A. Temporal response of plasma erythropoietin to hemorrhage in the ovine fetus. J. Soc. Gynecol. Invest. 9, 75-79 (2002).

23. Rollins, M. D., Maxwell, A. P., Afrasiabi, M., Halliday, H. L. \& Lappin, T. R. J. Cord blood erythropoietin, $\mathrm{pH}, \mathrm{PaO}_{2}$, and haemocrit following caesarean section before labour. Biol. Neonate 63, 147-152 (1993).

24. Stangenberg, M. et al. Erythropoietin concentrations in amniotic fluid and umbilical venous blood from Rh-immunized pregnancies. J. Perinat. Med. 21, 225-234 (1993)

25. Buescher, U., Hertwig, K., Wolf, C. \& Dudenhausen, J. W. Erythropoietin in amniotic fluid as a marker of chronic fetal hypoxia. Int. J. Gynecol. Obstet. 60, 257-263 (1998).

26. Philipps, A. F., Widness, J. A., Garcia, J. F., Raye, J. R. \& Schwartz, R. Erythropoietin in the chronically hyperglycemic fetal lamb. Proc. Soc. Exp. Biol. Med. 170, 42-47 (1982).

27. Escobar, J. et al. Amniotic fluid oxidative and nitrosative stress biomarkers correlate with fetal chronic hypoxia in diabetic pregnancies. Neonatology 103 181-186 (2013)
28. Song, J., Sundar, K., Gangaraju, R. \& Prchal, J. T. Regulation of erythropoiesis after normoxic return from chronic sustained and intermittent hypoxia. J. Appl. Physiol. 123, 1671-1675 (2017)

29. Pacher, P., Beckman, J. S. \& Liaudet, L. Nitric oxide and peroxynitrite in health and disease. Physiol. Rev. 87, 315-424 (2007).

30. Underwood, M. A., Gilbert, W. M. \& Sherman, M. P. Amniotic fluid: not just fetal urine anymore. J. Perinatol. 25, 341-348 (2005).

31. Jazayeri, A., Tsibris, J. C. \& Spellacy, W. N. Elevated umbilical cord plasma erythropoietin levels in prolonged pregnancies. Obstet. Gynecol. 92, 61-63 (1998).

32. Richey, S. D. et al. Markers of acute and chronic asphyxia in infants with meconium-stained amniotic fluid. Am. J. Obstet. Gynecol. 172, 1212-1215 (1995).

33. Jazayeri, A., Politz, L., Tsibris, J. C., Queen, T. \& Spellacy, W. M. Fetal erythropoietin levels in pregnancies complicated by meconium passage: does meconium suggest fetal hypoxia? Am. J. Obstet. Gynecol. 183, 188-190 (2000).

34. Morley, R. et al. Association between erythropoietin in cord blood of twins and size at birth: does it relate to gestational factors or to factors during labor or delivery. Pediatr. Res. 57, 680-684 (2005).

35. Girsen, A. et al. The relationship between human fetal cardiovascular hemodynamics and serum erythropoietin levels in growth-restricted fetuses. Am. J. Obstet. Gynecol. 196, 467 (2007). e1-e6.

36. Widness, J. A. et al. Correlation of the interpretation of fetal heart rate records with cord plasma erythropoietin levels. Br. J. Obstet. Gynaecol. 92, 326-332 (1985).

37. Kakuya, F. et al. Relationship between erythropoietin levels both in cord serum and amniotic fluid at birth and abnormal fetal heart rate records. Pediatr. Int. 44, 414-419 (2002).

38. Davis, L. E., Widness, J. A. \& Brace, R. A. Renal and placental secretion of erythropoietin during anemia or hypoxia in the ovine fetus. Am. J. Obstet. Gynecol. 189, 1764-1770 (2003).

39. Teramo, K., Loukovaara, M., Stefanovic, V., Hämäläinen, E. \& Andersson, S. The placenta increases its erythropoietin synthesis during fetal hypoxia in diabetic pregnancies. Reprod. Sci. 19, 258A-259A (2012).

40. Conrad, K. P., Benyo, D. F., Westerhausen-Larsen, A. \& Miles, T. M. Expression of erythropoietin by the human placenta. FASEB J. 10, 760-766 (1996).

41. Brines, M. \& Cerami, A. The receptor that tames the innate immune response. Mol. Med. 18, 486-496 (2012).

42. Juul, S. E. \& Pet, G. C. Erythropoietin and neonatal neuroprotection. Clin. Perinatol. 42, 469-481 (2015).

43. Rabie, T. \& Marti, H. H. Brain protection by erythropoietin: a manifold task. Physiology 23, 263-274 (2008).

44. Gruslin, A. \& Lemyre, B. Pre-eclampsia: fetal assessment and neonatal outcomes. Best Pract. Res. Clin. Obstet. Gynecol. 25, 491-507 (2011).

45. Juul, S. E., Anderson, S. K. \& Christensen, R. D. Erythropoietin and erythropoietin receptor in the developing human central nervous system. Pediatr. Res. 43, 40-49 (1998).

46. Marti, H. H. Erythropoietin and the hypoxic brain. J. Exp. Biology 207, 3233-3242 (2004).

47. Juul, S. E., Stallings, S. A. \& Christensen, R. D. Erythropoietin in the cerebrospinal fluid of neonates who sustained CNS injury. Pediatr. Res. 46, 543-547 (1999).

48. Noguchi, C. T., Asavaritikrai, P., Teng, R. \& Jia, Y. Role of erythropoietin in the brain Oncol. Hematol. 64, 159-171 (2007).

49. Brines, M. L. et al. Erythropoietin crosses the blood-brain barrier to protect against experimental brain injury. Proc. Natl. Acad. Sci. USA 97, 10526-10531 (2000).

50. Juul, S. E. et al. Erythropoietin concentrations in cerebrospinal fluid of nonhuman primates and fetal sheep following high-dose recombinant erythropoietin. Biol. Neonate 85, 138-144 (2004).

51. Neubauer, A. P., Voss, W., Wachtendorf, M. \& Jungmann, T. Erythropoietin improves neurodevelopmental outcome of extremely preterm infants. Ann. Neurol. 67, 657-666 (2010).

52. Mulkey, S. B. et al. Erythropoietin and brain magnetic resonance imaging findings in hypoxic-ischemic enecephalopathy: volume of acute brain injury and 1-year neurodevelopmental outcome. J. Pediatr. 186, 196-199 (2017).

53. Maheshwari, A. Role of cytokines in human intestinal villous development. Clin. Perinatol. 31, 143-155 (2004).

54. Espinoza, J. et al. Antimicrobial peptides in amniotic fluid: defensins, calprotectin and bacterial/permeability-increasing protein in patients with microbial invasion of the amniotic cavity, intra-amniotic inflammation, preterm labor and premature rupture of membranes. J. Matern. Fetal Neonat. Med. 13, 2-21 (2003).

55. Dasgupta, S. \& Jain, S. K. Protective effects of amniotic fluid in the setting of necrotizing enterocolitis. Pediatr. Res. 82, 584-595 (2017).

56. Kliegman, R. M. \& Fanaroff, A. A. Necrotizing enterocolitis. New Engl. J. Med. 310, 1093-1103 (1984).

57. Berseth, C. L. \& McCoy, H. H. Birth asphyxia alters neonatal intestinal motility in term neonates. Pediatrics 90, 669-673 (1992). 
58. Nikiforou, M., Willburger, C. \& de Jong, A. E. Global hypoxia-ischemia induced inflammation and structural changes in the preterm ovine gut which were not ameliorated by mesenchymal stem cell treatment. Mol. Med. 22, 244-257 (2016).

59. Juul, S. E., Joyce, A. E., Zhao, Y. \& Ledbetter, D. J. Why is erythropoietin present in human milk? Erythropoietin receptors in enterocytes of human and rat neonates. Pediatr. Res. 46, 263-268 (1999).

60. Ledbetter, D. J. \& Juul, S. E. Erythropoietin and the incidence of necrotizing enterocolitis in infants with very low birth weight. J. Pediatr. Surg. 35, 178-182 (2000).

61. $\mathrm{Yu}, \mathrm{Y}$. et al. Erythropoietin protects epithelial cells from excessive autophagy and apoptosis in experimental neonatal necrotizing enterocolitis. PloS ONE 8, e69620 (2013).

62. Ashley, R. A. et al. Erythropoietin stimulates vasculogenesis in neonatal rat mesenteric microvascular endothelial cells. Pediatr. Res. 51, 472-478 (2002).

63. El-Ganzoury, M. et al. Enteral granulozyte-colony stimulating factor and erythropoietin early in life improves feeding tolerance in preterm infants: a randomized controlled trial. J. Pediatr. 165, 1140-1145 (2014).

64. Pritchard, J. A. Fetal swallowing and amniotic fluid volume. Obstet. Gynecol. 28, 606-610 (1966)
65. Beall, M. H., van den Wijngaard, J. P., van Gemert, M. J. \& Ross, M. G. Amniotic fluid water dynamics. Placenta 28, 816-823 (2007).

66. Neu, J. \& Walker, W. A. Necrotizing enterocolitis. New Engl. J. Med. 364, 255-264 (2011).

67. Kling, P. J., Sullivan, T. M., Roberts, R. A., Philipps, A. F. \& Koldovsky, O. Human milk as a potential enteral source of erythropoietin. Padiatr. Res. 43, 216-221 (1998).

68. Juul, S. E. et al. Origin and fate of erythropoietin in human milk. Pediatr. Res. $\mathbf{4 8}$, 660-667 (2000).

69. Kling, P. J., Willeitner, A., Dvorak, B. \& Blohowiak, S. E. Enteral erythropoietin and iron stimulate erythropoiesis in suckling rats. J. Pediatr. Gastroenterol. Nutr. 46, 202-207 (2008).

70. Juul, S. E. et al. Erythropoietin acts as a trophic factor in neonatal rat intestine. Gut 49, 182-189 (2001).

71. Miller-Gilbert, A. L. et al. Enteral absorption of erythropoietin in the suckling rat. Pediatr. Res. 50, 261-267 (2001).

72. Britton, J. R. \& Christensen, R. D. Enteral administration of recombinant erythropoietin to preterm infants. J. Perinatol. 15, 281-283 (1995). 